\title{
The effect of irrigation solutions on the apical sealing ability in different root canal sealers
}

\section{Emre Bodrumlu(a) \\ Esra Parlak ${ }^{(b)}$ \\ Ebru Hazar Bodrumlu(c)}

(a) DDS, PhD, Associate Professor; (b)DDS, Research Assistant - Department of Endodontics, Faculty of Dentistry, Ondokuz Mayis University, Samsun, Turkey.

(c)DDS, Research Assistant, Department of Pediatric Dentistry, Faculty of Dentistry, Ondokuz Mayis University, Samsun, Turkey.

\section{Corresponding author:}

Emre Bodrumlu

Ondokuz Mayis University, Faculty of Dentistry

Department of Operative Dentistry and

Endodontics

Kurupelit-Samsun - Turkey

ZIP: 55139

E-mail: bodrumlu@omu.edu.tr

Received for publication on Feb 19, 2010 Accepted for publication on Apr 23, 2010

\begin{abstract}
The aim of this study was to assess the effect of three root canal irrigation solutions on the apical sealing ability of three root canal obturation materials: gutta-percha/AH plus or MM-seal and Resilon/ Epiphany SE. A total of 100 teeth with single straight root canals were randomly divided into three equal groups of 30 samples each, with the other 10 teeth (5 positive and 5 negative) used as controls. Each irrigation group was divided into three groups according to the use of three different root canal obturation materials $(n=10)$ : Gutta-percha with $\mathrm{AH}$ plus or MM-seal, Resilon with Epiphany SE. The crowns were removed at the cementoenamel junction with a diamond disc under water coolant. The root canals were prepared using step-back technique and irrigation with either sodium hypochlorite $(2.5 \%)$, chlorhexidine $(2 \%)$, or MTAD solutions. The roots were obturated with lateral condensation technique using one of the obturation materials. The root surfaces was coated with two layer nail varnish (except apex), placed in $2 \%$ methylene blue dye solution, and centrifuged at 3,000 rpm for 5 minutes. Irrigation solutions affected the apical sealing ability of all the sealers. The chlorhexidine irrigation solution exhibited higher apical leakage values than did MTAD and $\mathrm{NaOCl}$ in all canal sealers, although the MTAD irrigation solution groups showed the least leakage values. The apical sealing ability of $\mathrm{AH}$ plus, Epiphany SE and MM-seal root canal sealers decreased when the chlorhexidine was used as an irrigation solution.
\end{abstract}

Descriptors: Dental leakage; Irrigation; Root canal preparation; Root canal obturation; Endodontics.

\section{Introduction}

Endodontic therapy seeks the elimination of bacteria and its products from the root canal. Intracanal medications to disinfect the root canal system have been advocated to increase the success of the treatment. ${ }^{1}$ Studies have suggested $\mathrm{NaOCl}$ and chlorhexidine as irrigation solutions..$^{2-4}$ However, MTAD is a recently developed irrigating solution that consists of tetracycline, acetic acid and detergent. ${ }^{5}$ It has antimicrobial effect $^{6}$ and appears to be effective for removing smear layer along the entire length of the prepared root canal. ${ }^{5}$ It is able to remove both organic and inorganic debris. ${ }^{7}$

Many endodontic filling materials have been used in an attempt to improve apical seal during root canal therapy. The use of gutta-percha 
with a sealer is currently the most common method for obturation. AH plus and MM-seal root canal sealers are epoxy resin based sealers used with gutta-percha. However, Resilon core material and Epiphany SE (Pentron Clinical Technologies, Wallingford, CT, USA) are popular obturation materials introduced as an alternative to gutta-percha and traditional root canal sealers. Resilon core material is a thermoplastic synthetic polymer-based root canal filling material and Epiphany SE is a self etch resin based sealer that eliminates the priming step.

Various methods ${ }^{8}$ have been used to evaluate the apical sealing property of root canal filling materials. Because of its sensitivity, ease of use, and convenience, the most common measurement used is the centrifuging dye penetration method. ${ }^{8}$ The depth of dye penetration represents the gap between the root filling and the canal walls. The assessment of linear dye penetration apically or coronally is the most common in vitro method for examining the adaptation of a root filling to the canal walls.

The aim of this study was to assess the effect of three different root canal irrigation solutions on the apical sealing ability of three different root canal obturation materials: gutta-percha with $\mathrm{AH}$ plus or MM-seal and Resilon with Epiphany SE.

\section{Material and Methods}

The teeth, extracted for periodontal/orthodontic reasons, were collected from the clinics of oral surgery. In total, 100 teeth with single straight root canals were randomly divided into three equal groups of 30 samples each. The other 10 teeth (5 positive and 5 negative) were used as controls. Each irrigation group was further divided into three groups according to the use of three different root canal obturation materials $(\mathrm{n}=10)$ : Gutta-percha with AH plus (Dentsply, Konstanz, Germany) or MMseal (Micro-Mega, Besançon, France), Resilon with Epiphany SE (Pentron Clinical Technologies, Wallingford, CT, USA).

The crowns were removed at the cementoenamel junction with a diamond disc under water coolant. The canal lengths were visually established by placing a size $15 \mathrm{~K}$ file (Kerr, Romulus, MI, USA) into each root canal until the tip of the file was visible at the tip of the apical foramen. The working length was established $1 \mathrm{~mm}$ short of the apex. The canal systems were instrumented to the working length with a size $45 \mathrm{~K}$ file by using a step-back technique and irrigated with either $2.5 \%$ sodium hypochlorite (Wizard, Rehber Chemistry, Istanbul, Turkey), 2\% chlorhexidine (Klorhex, Drogsan, Ankara, Turkey), or MTAD (Dentsply, Washington, USA) solutions. Finally, the root canals were flushed with $5 \mathrm{ml}$ of 17\% EDTA (Canal +, Septodont, France) for $1 \mathrm{~min}$ and $2 \mathrm{ml}$ of saline solution and then dried with paper points.

Roots were filled using the lateral condensation technique with gutta-percha/AH plus sealer, guttapercha/MM-seal and Resilon/Epiphany SE. For the Epiphany SE, light curing was applied for $40 \mathrm{sec}-$ onds with a standard light-curing unit (Hilux, Ledmax-550, Benlioglu, Turkey), according to the manufacturer's instructions.

The root surfaces were coated with nail varnish (except apex). However, in the positive control group, the roots without filling with core material and sealer were coated with two layers of nail varnish except for the apical foramen. The negative controls were filled with core material and sealer, and then were completely coated with two layers of nail varnish.

After the filling process, all samples were stored in saline solution at $37^{\circ} \mathrm{C}$ for 48 hours. All specimens were placed in $2 \%$ methylene blue dye solution, and centrifuged at 3,000 rpm for $5 \mathrm{~min}$.

The specimens were washed under running tap water for $5 \mathrm{~min}$. The roots were then longitudinally grooved with a diamond disc and split with a chisel, ensuring that the root canal filling was not penetrated, and then split into halves by levering with a plaster knife. The dye penetration was measured from the apical to the coronal part of the root canal to which the dye had penetrated using a stereomicroscope with ocular micrometer (Olympus BX 50, Olympus, Tokyo, Japan). Then, the mean values of leakage for each group were calculated and recorded. The Kruskal-Wallis and Mann-Whitney-U tests were performed for multiple comparisons to compare statistically significant differences. The level of significance was set at $\alpha=0.05$. 


\section{Results}

All groups demonstrated apical leakage. The positive-control specimens demonstrated total dye penetration of the root canal system whilst the negative control teeth had no dye penetration into the roots.

The mean values of the apical sealing are showed in Table 1. Irrigation solutions affected the apical sealing ability of the sealers. The chlorhexidine irrigation solution exhibited higher apical leakage values than did MTAD and $\mathrm{NaOCl}$ in all canal sealers $(\mathrm{p}<0.05)$. However, the MTAD irrigation solution groups showed the least leakage values in all irrigation groups. But no statistically differences have been determined among the three sealers in terms of each irrigation group $(\mathrm{p}>0.05)$.

\section{Discussion}

Endodontic treatment employs an aseptic technique during which the infected root canal is disinfected using a combination of mechanical and chemical procedures. A chemomechanical approach to disinfection of root canals has been adopted in modern endodontics. ${ }^{9}$ In addition to that hermetic obturation and complete coronal and apical seal is one of the most important processes of endodontic treatment. Apical and coronal leakages have been shown to be important reasons for root canal treatment failure. ${ }^{9,10}$ A perfect apical seal is also essential for the prevention of apical percolation. The sealing quality of a root canal filling depends a great deal on the sealing ability of the sealer.

Several techniques ${ }^{8,9}$ have been used to analyze the sealing ability with regard to root canal fillings, including evaluation of leakage of bacteria, human saliva, protein complex, fluid filtration and dye leakage. However, dyes can chemically interact with sealing materials or dentin, which may influence its diffusion or promote tracer decoloration, impairing an adequate marginal leakage evaluation. ${ }^{8,11}$ Because of their small molecular size, ${ }^{12}$ dye penetration has been used as a dependent measure of sealing ability; however, whether dyes mimic penetration of microorganisms or antigens is still not known. ${ }^{13}$ Moreover, entrapped air in the canal filling may falsify dye penetration depth, ${ }^{14,15}$ suggesting the application of vacuum techniques or centrifugation, ${ }^{15,16}$ even if previous studies ${ }^{17,18}$ showed that dye penetration did not differ whether centrifugation was applied or not. In addition to that Matloff et al. ${ }^{19}$ (1982) reported no correlation between a dye penetration and a radioisotope method. Similarly, a study by Barthel et al. ${ }^{20}$ (1999) showed no correlation between dye penetration and bacterial leakage test methods. Moreover, Pommel et al. ${ }^{21}$ (2001) found no correlation between dye penetration, electrochemical and fluid filtration methods. Hence, the centrifugation method was chosen for the present study.

The studies of Onay et al.22 (2006) and also of Bodrumlu and Tunga ${ }^{23}$ (2007) found no significant differences between Epiphany/Resilon and AH plus/ gutta-percha root canal filling materials in terms of the apical sealing ability when irrigating the canals with $\mathrm{NaOCl}$. The findings of the current study are consistent with those of these other studies.

On the contrary, Park et al. ${ }^{24}$ (2004) found that root canals filled with AH plus/gutta-percha treated with MTAD yielded significantly less coronal leakage than roots filled with $\mathrm{AH}$ plus/gutta-percha treated with sodium hypochlorite using a passive dye leakage method. However, our results from the gutta-percha/AH Plus groups irrigating with $\mathrm{NaOCl}$ or MTAD disagree with the results of Park et al.'s study $^{24}$ (2004). This discrepancy might be due to

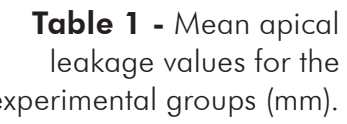

Table 1 - Mean apical experimental groups ( $\mathrm{mm})$.

\begin{tabular}{c|c|c|c|c}
\hline \multirow{2}{*}{$\begin{array}{c}\text { Irrigation } \\
\text { solutions }\end{array}$} & \multicolumn{4}{|c}{ Root canal obturation materials } \\
\cline { 2 - 5 } & Gutta percha/ AH Plus & Gutta percha/ MM-seal & Resilon/ Epiphany SE & $P$ value \\
\hline $\mathrm{MTAD}$ & $2.65 \pm 0.36^{\mathrm{a}}$ & $2.51 \pm 0.33^{\mathrm{a}}$ & $2.54 \pm 0.29^{\mathrm{a}}$ & $\mathrm{p}>0.05$ \\
\hline $\mathrm{NaOCl}$ & $2.75 \pm 0.32^{\mathrm{a}}$ & $2.58 \pm 0.31^{\mathrm{a}}$ & $2.6 \pm 0.35^{\mathrm{a}}$ & $\mathrm{p}>0.05$ \\
\hline $\mathrm{CHX}$ & $3.44 \pm 0.34^{\mathrm{b}}$ & $3.18 \pm 0.28^{\mathrm{b}}$ & $3.27 \pm 0.29^{\mathrm{b}}$ & $\mathrm{p}>0.05$ \\
\hline
\end{tabular}

Equal letters: no statistically significant differences among the groups. Different letters: statistically significant difference among the groups. 
differences in the chosen test methods, the leakage region, and the application time of MTAD.

Only one study ${ }^{25}$ that assessed the sealing ability of MM-seal/gutta percha with that of AH plus on non-radiation and irradiation groups was reported. Bodrumlu et al.'s study ${ }^{25}$ (2009) demonstrated that in the nonradiation groups, the apical sealing abilities of MM-seal/gutta percha and AH plus/guttapercha were similar when irrigating the canals with $\mathrm{NaOCl}$, testing with a centrifuged dye penetration method. These results concur with those of the present study.

The chlorhexidine gluconate in the form of gel has great potential for use as an endodontic irrigant. ${ }^{26}$ Compared to $\mathrm{CHX}$ groups, the $\mathrm{NaOCl}$ and MTAD solutions seem to create a more favorable surface for the root canal filling materials to achieve a better apical seal. On the contrary, this outcome may be attributed to the fact that the CHX solutions do not have the ability to dissolve organic tissues from the root canal system. Additionally, Carvalho et al. ${ }^{27}$ (2008) stated that $\mathrm{CHX}$ endodontic irrigants were not as efficient in cleansing the root canals. Hence, the remnants of these organic materials may prevent the adhesion of the sealer to the root canal walls, when irrigating with $\mathrm{CHX}$.

Various irrigation protocols have been used during the root canal treatment, and evidence strongly favors $\mathrm{NaOCl}, \mathrm{MTAD}$ and $\mathrm{CHX}$ solutions. ${ }^{28}$ Thus this study was designed to assess the apical sealing

\section{References}

1. Abbott PV. Medicaments: aids to success in endodontics. Part 2. Clinical recommendations. Aust Dent J. 1990 Dec;35(6):491-6.

2. Mohammadi Z, Abbott PV. The properties and applications of chlorhexidine in endodontics. Int Endod J. 2009 Apr;42(4):288-302.

3. Ferguson DB, Marley JT, Hartwell GR. The effect of chlorhexidine gluconate as an endodontic irrigant on the apical seal: long-term results. J Endod. 2003 Feb;29(2):91-4.

4. Haapasalo M, Orstavik D. In vitro infection and disinfection of dentinal tubules. J Dent Res. 1987 Aug;66(8):1375-9.

5. Torabinejad M, Khademi AA, Babogoli J. A new solution for the removal of smear layer. J Endod. 2003 Mar;29(3):170-5. ability of three root canal sealers when these three different irrigation agents were used. Sodium hypochlorite, which is generally used in dental clinics, was effective for cleaning the apical part of root canals, ${ }^{29}$ and in concentrations ranging from 1.0 to $6.0 \%$ it was effective in removing debris from the root canal. ${ }^{30}$ However, in the present study, $2.5 \%$ $\mathrm{NaOCl}$ was preferred. Chlorhexidine gluconate has good substantivity and has the ability to adhere to hydroxyapatite crystals in dentine. It could potentially remain active following root canal treatment. ${ }^{28}$ However, its efficacy on apical sealing ability of the root canal obturation materials has not been reported yet. MTAD is a recently popular irrigation material. It dissolves organic and inorganic remnants in the root canal and also removes the smear layer, ${ }^{5-7}$ but there are few studies related to its effect on the sealing ability of different root canal fillings. It is well known that when the surface area of dentin exposed to this sealer is increased, the adhering and penetrating capacity of root canal sealers is improved and a better seal is expected.

\section{Conclusion}

The apical sealing ability of AH plus, MM-seal and Epiphany SE root canal sealers decreased when the chlorhexidine was used as an irrigation solution. Among the irrigation regimens assessed in this study, the MTAD solution yielded the best overall results and provided best apical sealing ability.

6. Shabahang S, Torabinejad M. Effect of MTAD on Enterococcus faecalis-contaminated root canals of extracted human teeth. J Endod. 2003 Sep;29(9):576-9.

7. Beltz RE, Torabinejad M, Pouresmail M. Quantitative analysis of the solubilizing action of MTAD, sodium hypochlorite, and EDTA on bovine pulp and dentine. J Endod. 2003 May;29(5): 334-7.

8. Veríssimo DM, do Vale MS. Methodologies for assessment of apical and coronal leakage of endodontic filling materials: a critical review. J Oral Sci. 2006 Sep;48(3):93-8.

9. Rhodes JS. Advanced Endodontics Clinical Retreatment and Surgery. $1^{\text {st }}$ ed., London: Taylor \& Francis Inc, 2006. Irrigation and Medication. p. 129-46. 
10. Cobankara FK, Adanir N, Belli S. Evaluation of the influence of smear layer on the apical and coronal sealing ability of two sealers. J Endod. 2004 Jun;30(6):406-9.

11. Oztan MD, Ozgey E, Zaimoglu L, Erk N. The effect of various root canal sealers on India ink and different concentrations of methylene blue solutions. J Oral Sci. 2001 Dec;43(4):245-8.

12. Kersten HW, Moorer WR. Particles and molecules in endodontic leakage. Int Endod J. 1989 May;22(3):118-24.

13. Barthel CR, Moshonov J, Shuping G, Òrstavik D. Bacterial leakage versus dye leakage in obturated root canals. Int Endod J. 1999 Sep;32(5):370-5.

14. Spangberg LSW, Acierno TG, Cha BY. Influence of entrapped air on the accuracy of leakage studies using dye penetration methods. J Endod. 1989 Nov;15(11):548-51.

15. Oliver CM, Abbott PV. Entrapped air and its effects on dye penetration of voids. Endod Dent Traumatol. 1991 Jun; 7(3):135-8.

16. Boussetta F, Bal S, Romeas A, Boivin G, Magloire H, Farge P. In vitro evaluation of apical microleakage following canal filling with a coated carrier system compared with lateral and thermomechanical gutta-percha condensation techniques. Int Endod J. 2003, May;36(5):367-71.

17. Pathomvanich S, Edmunds DH. Variation in the microleakage produced by four different techniques in root fillings in a simulated root canal model. Int Endod J. 1996, May; 29(3): 156-62.

18. Dickson SS, Peters DD. Leakage evaluation with and without vacuum of two gutta-percha filling techniques. J Endod.1993 Aug;19(8):398-403.

19. Matloff IR, Jensen JR, Singer L, Tabibi A. A comparison of methods used in root canal sealability studies. Oral Surg Oral Med Oral Pathol. 1982 Feb;53(2):203-8.
20. Barthel CR, Moshonov J, Shuping G, Orstavik D. Bacterial leakage versus dye leakage in obturated root canals. Int Endod J. 1999 Sep;32(5):370-5.

21. Pommel L, Jacquot B, Camps J. Lack of correlation among three methods for evaluation of apical leakage. J Endod. 2001 May;27(5):347-50.

22. Onay EO, Ungor M, Orucoglu H. An in vitro evaluation of the apical sealing ability of a new resin-based root canal obturation system. J Endod. 2006 Oct;32(10):976-8.

23. Bodrumlu E, Tunga U. The apical sealing ability of a new root canal filling material. Am J Dent. 2007 Oct;20(5):295-8.

24. Park DS, Torabinejad M, Shabahang S. The effect of MTAD on the coronal leakage of obturated root canals. J Endod. 2004 Dec;30(12):890-2.

25. Bodrumlu E, Avsar A, Meydan AD, Tuloglu N. Can radiotherapy affect the apical sealing ability of resin-based root canal sealers? J Am Dent Assoc. 2009 Mar;140(3):326-30.

26. Ferraz CC, Figueiredo de Almeida Gomes BP, Zaia AA, Teixeira FB, de Souza-Filho FJ. In vitro assessment of the antimicrobial action and the mechanical ability of chlorhexidine gel as an endodontic irrigant. J Endod. $2001 \mathrm{Jul} ; 27(7): 452-5$.

27. Carvalho AS, Camargo CH, Valera MC, Camargo SE, Mancini MN. Smear layer removal by auxiliary chemical substances in biomechanical preparation: a scanning electron microscope study. J Endod. 2008 Nov;34(11):1396-400.

28. Zehnder M. Root canal irrigants. J Endod. 2006 May;32(5); 389-98.

29. Baumgartner JC, Brown CM, Mader CL, Peters DD, Shulman JD. A scanning electron microscope evaluation of root canal debridement using saline, sodium hypochlorite, and citric acid. J Endod. 1984 Nov;10(11): 525-31.

30. Baumgartner JC, Cuenin PR. Efficacy of several concentrations of sodium hypochlorite for root canal irrigation. J Endod. 1992 Dec;18(12): 605-12. 